\title{
Cardiovascular Prevention of Cognitive Decline
}

\author{
Jean-Jacques Monsuez, ${ }^{1}$ Aude Gesquière-Dando, ${ }^{2}$ and Sofia Rivera ${ }^{3}$ \\ ${ }^{1}$ AP-HP, Hôpital René Muret, Hôpitaux Universitaires de Paris Seine-Saint-Denis, Policlinique Médicale, \\ Avenue du Docteur Schaeffner, 93270 Sevran, France \\ ${ }^{2}$ Service de Neurologie, Hôpital de la Timone, 13385 Marseille, France \\ ${ }^{3}$ Service d'Oncologie-Radiothérapie, AP-HP Hôpital Saint-Louis, 75475 Paris, France
}

Correspondence should be addressed to Jean-Jacques Monsuez, jean-jacques.monsuez@rmb.aphp.fr

Received 8 September 2010; Accepted 23 December 2010

Academic Editor: Christina Chrysohoou

Copyright (C 2011 Jean-Jacques Monsuez et al. This is an open access article distributed under the Creative Commons Attribution License, which permits unrestricted use, distribution, and reproduction in any medium, provided the original work is properly cited.

\begin{abstract}
Midlife cardiovascular risk factors, including diabetes, hypertension, dyslipemia, and an unhealthy lifestyle, have been linked to subsequent incidence, delay of onset, and progression rate of Alzheimer disease and vascular dementia. Conversely, optimal treatment of cardiovascular risk factors prevents and slows down age-related cognitive disorders. The impact of antihypertensive therapy on cognitive outcome in patients with hypertension was assessed in large trials which demonstrated a reduction in progression of MRI white matter hyperintensities, in cognitive decline and in incidence of dementia. Large-scale database correlated statin use and reduction in the incidence of dementia, mainly in patients with documented atherosclerosis, but clinical trials failed to reach similar conclusions. Whether a multitargeted intervention would substantially improve protection, quality of life, and reduce medical cost expenditures in patients with lower risk profile has not been ascertained. This would require appropriately designed trials targeting large populations and focusing on cognitive decline as a primary outcome endpoint.
\end{abstract}

\section{Introduction}

As a result of the increased life expectancy, the proportion of older people with cognitive impairment increases continuously. Alzheimer disease, which affects about 35 million people worldwide today, is estimated to afflict more than 100 million people by 2050 [1-3]. Amnestic mild cognitive impairment is found in about $20 \%$ of people older than 85 years with a conversion rate to Alzheimer disease of $10 \%-$ $15 \%$ per year [4]. As a consequence, management of patients with cognitive disorders is quite common in daily cardiology practice. More recently, several studies have highlighted the deleterious role of cardiovascular risk factors on the incidence and progression of cognitive disorders in elderly people. This endorses the potential protection provided by therapeutic cardiovascular risk control.

\section{Vascular Dementia and Alzheimer Disease}

Besides Alzheimer disease, which account for about $60 \%-$ $80 \%$ of cases of dementia in the elderly, vascular dementia has been increasingly recognized over the past decades as a late consequence of previous symptomatic [5] or clinically silent [6] stroke in patients with cerebrovascular disease, multifocal atherosclerosis, and cardiovascular risk factors. The spectrum of vascular dementia has subsequently expanded to include patients without stroke past history in whom brain magnetic resonance imaging (MRI) showed subcortical lesions such as white matter hyperintensities (Figure 1), lacunar infarctions and/or microhemorrhages [7]. Similar MRI lesions were also found in patients with cardiovascular risk factors only, especially hypertension $[8,9]$, and, paradoxically, in patients with Alzheimer disease. In addition, several studies showed that a past history of stroke or cerebral microinfarcts were associated with an increased risk of subsequent Alzheimer disease, its early onset and/or its accelerated clinical progression rate [10-14]. Consistent with these findings, pathological examinations revealed cerebral damages belonging to both forms of dementia in some instances, for example, coexisting senile plaques and neurofibrillary tangles with vascular lesions [15]. Furthermore, pathways common to progression of 


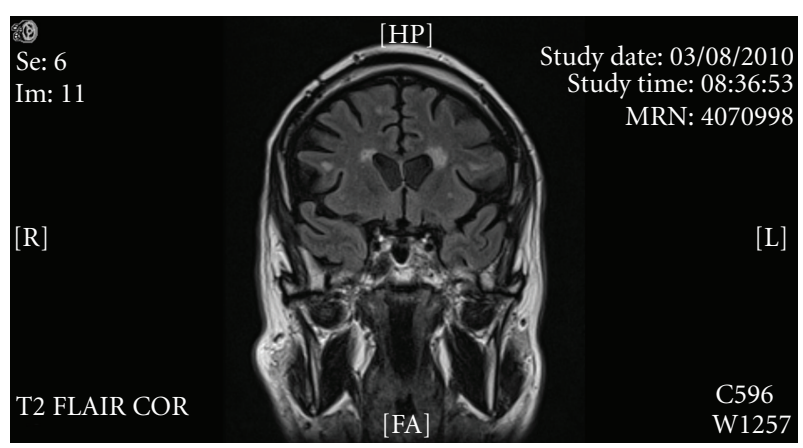

FIGURE 1: Periventricular and subcortical white matter hyperintensities. MRI, T2-weighted sequence, flair.

both diseases were also reported [16]. Finally, epidemiological studies demonstrated a correlation between late life occurrence of Alzheimer disease and the presence of midlife hypertension or cardiovascular risk factors $[17,18]$.

Accordingly, the diagnosis of vascular dementia, as defined using specifically selected clinical criteria only [23] has turned to a revisited framework in which vascular dementia and Alzheimer disease interplay with each other. Their incidence, the delay after which they appear, and their progression rate are promoted by cardiovascular risk factors [24]. As a result, control of cardiovascular risk factor may delay onset and slow down progression of cognitive disorders in elderly.

\section{Diabetes}

Cognitive disorders are observed with an increased prevalence among diabetics who suffered previous stroke [25]. In the Honolulu-Asia Aging Study (HAAS), a cardiovascular risk factor study initiated in 1965, cognitive function and brain MRI were assessed between 2004 and 2006 in 3734 survivors with regards to the presence of type 2 diabetes $(38 \%$ of the population). Subjects with diabetes type 2 or impaired glucose tolerance have an increased risk of cerebral lacunes (odds ratio, OR: 1.6), hippocampal atrophy (OR: 1.7), and microinfarcts (OR: 1.9). The prevalence of either vascular dementia or Alzheimer disease with cardiovascular disease was $5.4 \%$ in diabetics and $2.9 \%$ and $2.5 \%$ in nondiabetics, respectively [26].

Although cognitive disorders are common in older diabetics, they develop slowly. They are limited to mild cognitive disorders in most patients for many years before more severe manifestations occur [35].

Several mechanisms have been advocate.

(i) Hyperinsulinemia: after crossing the blood brain barrier, insulin competes in the brain with amyloid $\beta$ for insulin degradising enzyme, a pathway which is enhanced in patients with the apolipoprotein APOE$\varepsilon 4$ allele [36]. Conversely, rosiglitazone reduces progression of cognitive impairment and Alzheimer disease in diabetics by decreasing insulin blood levels and insulin resistance [37]. (ii) Advanced glycosylation end products (AGEs) resulting from glucose intolerance accumulate in senile plaque and neurofibrillary tangles. This pathway is enhanced by amyloid $\beta$ binding to membrane AGEs receptors and further neuronal injury [36].

\section{Hypertension}

Large-scale epidemiological cohort studies initiated 4 decades ago correlated midlife hypertension to late life cognitive impairment. Among 392 aged survivors of the NHLBI Twin study, prevalence of dementia and white matter hyperintensities was higher in subjects whose blood pressure was increased at the follow-up visit in 1970, 1980, and 1985 [38]. Similar correlations between midlife hypertension and late life prevalence of dementia and/or extent of white matter hyperintensities were found in several other longitudinal follow-up studies [39-41].

Among 226 participants of PROGRESS (Perindopril Protection against Recurrent Stroke Study) in whom brain MRI was performed, the extent of white matter hyperintensities predicted development of dementia during followup: the relative risk increased from $1.6(0.4-6)$ in patients with mild to moderate lesions to 7.7 (2.1-28.6) in patients with severe lesions [41]. Progression of white matter hyperintensities over time is increased in patients with either systolic or diastolic elevated blood pressure [40-42]. A similar relationship between midlife systolic or diastolic blood pressure levels and subsequent hippocampal volume reduction was observed in the Honolulu-Asia Aging Study [43].

The impact of antihypertensive therapy on cognitive impairment in patients with high blood pressure (HBP) was assessed in several trials. SCOPE (Study on Cognition and Prognosis in the Elderly) included 4964 patients with mild hypertension $(160<\mathrm{SBP}<179 \mathrm{mmHg} ; 90<\mathrm{DBP}<$ $99 \mathrm{mmHg}$ ), aged 70 to 89 years and Mini Mental State Examination (MMSE) score $\geq 24$. Double-blind treatment consisted of candesartan or placebo. Open label therapy was added to control blood pressure. Blood pressure reduction was significantly higher in patients receiving candesar$\tan (21.7 / 10.8 \mathrm{mmHg})$ than in controls $(18.5 / 9.2 \mathrm{mmHg})$, resulting in a decreased stroke incidence after a 3.7 years followup $(-23.6 \%)$. There were no significant differences in MMSE scores between intervention and control group [44]. However, when patients were stratified according to baseline MMSE score, the incidence of dementia was higher among those with a low cognitive function $(24<\mathrm{MMSE}<28)$ when compared with those with a preserved cognitive function (MMSE > 28). Among patients with a low baseline cognitive function, the MMSE score declined less in the candesartan group (mean difference $0.49, P=.04$ ). Of note, patients with a low baseline cognitive function were older and had more cardiovascular risk factors [45].

Although designed to include cognitive function in the assessment of benefits of antihypertensive therapy in elderly, HYVET (Hypertension in the Very elderly Trial) failed to reach definite conclusions about this specific issue. Indeed, the trial was stopped early after 2.2 years because 
treatment resulted in a reduction in stroke and total mortality. This double-blind, placebo-controlled trial enrolled 3336 patients aged 80 years or more with hypertension $(160<\mathrm{SBP}<200 \mathrm{mmHg}$; DBP < $110 \mathrm{mmHg})$. Patients received inda-pamide ( $1.5 \mathrm{mg}$ daily) \pm perindopril $(2-4 \mathrm{mg}$ daily) or placebo. Although blood pressure was lower in the intervention group, the difference in dementia incidence rate was not statistically different between patients receiving therapy and controls (33 versus 38 per 1000 patients-years). However, when the authors combined their data in a metaanalysis with other placebo-controlled trials of antihypertensive treatment, results reached statistical significance [46].

Two other trials, PROGRESS and SYST-EUR, provided convincing data on the protection of cognitive decline in older patients treated with antihypertensive agents.

PROGRESS (Perindopril Protection against recurrent Stroke Study) included 6105 patients (mean age: 64 years) with previous stroke or transient cerebral ischemic attack and assessed incidence of (vascular) dementia and cognitive decline (MMSE score reduction >2) with regards to therapy consisting of either perindopril/indapamide or placebo. After a 3.9-year mean followup, treatment reduced the incidence of dementia by $12 \%$, of cognitive decline by $19 \%$ and of a combination of cognitive decline or recurrent stroke by $34 \%$ [47]. A substudy compared baseline and followup brain MRIs in 192 patients to assess progression of white matter hyperintensities in patients receiving therapy and in controls. Whereas the extent of baseline white matter hyperintensities was similar in both groups, new hyperintensities appeared in $16 \%$ of controls and $9 \%$ of patients receiving therapy. Although these changes were not statistically significant, the mean total volume of new white matter hyperintensities was reduced in the treatment group ( 0.4 versus $\left.2 \mathrm{~mm}^{3}, P=.012\right)$ [48].

Whereas PROGRESS by selecting patients with cerebrovascular disease targeted the impact of antihypertensive therapy on vascular dementia mainly, SYST-EUR (Systolic Hypertension in Europe) was intended to include a broad population, consisting of patients $>60$ years with systolic hypertension $(160<\mathrm{SBP}<219 \mathrm{mmHg}$; DBP $<95 \mathrm{mmHg})$. The initial double-blind trial randomized 579 patients with either nitrendipine (10-40 mg daily), completed by enalapril (5-20 mg daily) and hydrochlorothiazide (12.5-25 mg daily) if required to control BP or placebo [49]. After a 2year followup, the trial was continued on the basis of an open-label active treatment study in which a total of 2902 patients received therapy. After a mean follow up of 3.9 years, blood pressure control, though improved, remained suboptimal in the control group $(156 \pm 12 / 82.5 \pm 6$ versus $149 \pm 9.7 / 79 \pm 6 \mathrm{mmHg}$ at the last follow up visit), in connection with fewer patients receiving antihypertensive drugs (nitrendipine: $48.1 \%$ versus $70.2 \%$; enalapril: $26.4 \%$ versus $35.4 \%$; hydrochlorothiazide: $11.4 \%$ versus $18.4 \%$ ). This was associated with a decreased incidence of dementia in the intervention group when compared with the control group (dementia all causes: 3.3 versus 7.4 per 1000 patientyear; Alzheimer disease: 1.9 versus 5 per 1000 patient-year; mixed or vascular dementia: 1.1 versus 2.1 per 1000 patientyear) [50].

\section{Hyperlipemia}

Although increased levels of total and LDL-cholesterol are associated with cardiovascular risk, atherosclerosis, and vascular dementia, similar correlations failed to be demonstrated with the incidence of Alzheimer disease [51]. However, Helzner et al. showed that both parameters are correlated with Alzheimer disease progression, each $10 \mathrm{mG} / \mathrm{dL}$ decrease in either being associated with a $0.10-\mathrm{SD}$ decrease in cognitive score per year of followup [52].

Large-scale database correlated statin use and reduction in the incidence of dementia. Using the US Veteran Affairs database which collected information on approximately 4.5 million subjects and 110 million prescription annually, Wolozin et al. showed a strong reduction in the incidence of dementia in patients receiving simvastatin $(\mathrm{HR}=0.46)$, a moderate reduction in those receiving atorvastatin $(\mathrm{HR}=$ 0.91), whereas no change was observed among patients treated with lovastatin [53]. Similar results were obtained using a nested case-control study on 309 patients with Alzheimer disease at the US Veteran Affairs Medical Center of Birmingham between 1997 and 2002. Patients treated with statins had a 39\% lower risk of Alzheimer disease related to nonstatin users. Of note, this association was observed in patients with ischemic heart disease, cerebrovascular disease, or hypertension but not among those without any of these conditions [54]. Conversely, data from the specialized register of the Cochrane dementia and cognitive improvement group, which analyzed the 2 double-blind, randomized, placebo-controlled trials HPS and PROSPER, failed to reach similar conclusions. Indeed, among the 5804 patients aged 70 to 82 years included in PROSPER, there was no difference in cognitive performance nor in incidence of dementia between pravastatin treated and placebo group. Also, no difference in incidence of dementia or in cognitive performance tests decline was noted in HPS, in which 5806 patients over 70 years received simvastatin or placebo [55].

Thus, although several epidemiological and clinical trials provided evidence and a rationale basis for a preventive role of statins in Alzheimer disease [56], one should also argue that many others showed that this benefit was limited to patients with cerebrovascular, coronary artery disease, or hypertension.

\section{Diet and Physical Activity}

A lower level of physical performance in ageing adults is associated with an increased risk of dementia. In a prospective cohort study of 2288 people 65 years and older with a 6-years followup, Wang et al. observed an age-specific incidence rate of dementia, reaching 53.1 per 1000 personyear for participants who scored lower on a performancebased physical function test at baseline compared with 17.4 per 1000 person-years for those who scored higher. These impairments in physical function, which are interconnected with onset of cognitive decline, occur during the early, subclinical, stage of the disease. Conversely, a higher level of physical function is associated with a delayed onset of Alzheimer disease [57]. 
TABLE 1: Age-dependent prevalence of dementia (\%) in selected populations.

\begin{tabular}{|c|c|c|c|c|c|c|c|c|}
\hline & Population & Criteria & Disease & $65-69$ yrs & $70-74$ yrs & $75-79$ yrs & $80-85$ yrs & $>85 \mathrm{yrs}$ \\
\hline Hofmanet al. [19] & 12 European surveys & clinical & & 1.4 & 4.1 & 5.7 & 13 & 21.6 \\
\hline Ritchie and Kildea [20] & 9 US and European surveys & clinical & & 1.5 & 3.5 & 6.8 & 13.6 & 22.3 \\
\hline Anstey et al. [21] & Australia & MMSE & & 3.78 & 5.16 & 10.6 & 16.3 & 22.3 \\
\hline Dong et al. [22] & China & clinical & $\mathrm{AD}(\mathrm{w} / \mathrm{m})$ & $0.5 / 0.3$ & $1.8 / 0.9$ & $4.4 / 2.3$ & $11 / 3.8$ & $23.4 / 10.6$ \\
\hline Dong et al. [22] & China & clinical & $\mathrm{VD}(\mathrm{w} / \mathrm{m})$ & $2 / 0.9$ & $2 / 0.4$ & $1.9 / 0.6$ & $1.1 / 1.8$ & $0.4 / 0$ \\
\hline
\end{tabular}

AD: Alzheimer disease. VD: vascular dementia w/m: women/men.

TABle 2: Prevalence of dementia (clinical criteria) in people aged > 65 years.

\begin{tabular}{llc}
\hline & Country & Prevalence rate (\%) \\
\hline $\begin{array}{l}\text { Fitzpatrick et al. [27] } \\
\text { Graham et al. [28], }\end{array}$ & USA & 6.3 \\
Hébert et al. [29] & Canada & 5.3 \\
$\begin{array}{l}\text { Berr et al. [30], } \\
\text { Riedel-Heller et al. [31] }\end{array}$ & $\begin{array}{l}\text { countries } \\
\text { (EURODEM) }\end{array}$ & 5.9 \\
Lobo et al. [32] & $\begin{array}{l}\text { Spain } \\
\text { 6 countries, }\end{array}$ & 5.2 \\
Nitriniet al. [33] & South America & 7.1 \\
Kalaria et al. [34] & India & 3.4 \\
$\begin{array}{l}\text { Dong et al. [22], } \\
\text { Kalaria et al. [34] }\end{array}$ & China & 3.1 \\
\hline
\end{tabular}

Several studies have shown that a healthy lifestyle, including diet and exercise training, may prevent cognitive decline in the elderly. Their results migh however have been biased by confounding factors such as educational and socioeconomic status and the impact of diet and exercise on cardiovascular risk factors. These drawbacks were not supported by recent studies suggesting that diet and exercise prevent and slow down dementia independently of such confounding factors.

The WHICAP (Washington Heights-Inwood Columbia Aging Project) cohort study enrolled 1880 Medicare beneficiaries in Northern Manhattan in 1991. Food consumption, a Mediterranean-type diet adherence score and a physical activity score were documented. Neuropsychological tests were repeated every 18 months from inclusion through 2006. Dementia developed in 282 subjects. Patients adhering to the Mediterranean-type diet and participating to physical activities with the highest scores have a lower risk of subsequent Alzheimer disease in a model adjusted for age, sex, ethnicity, education, apolipoprotein E genotype, caloric intake, body mass index, smoking status, leisure activities, and a comorbid index [58].

Similar results were obtained among 1410 participants included in the Bordeaux cohort study. After a 5-year followup, higher adherence to the Mediterranean-type diet was associated with a slower MMSE cognitive decline [59].

\section{Risk Profiles for Dementia}

7.1. Multifactorial Prevention. Although numerous studies have linked cardiovascular risk factors profile to subsequent incidence of dementia, most interventions to prevent cognitive decline were performed on a single risk factor control basis. Whether multifactorial prevention will provide substantially improved protection has not been ascertained, especially in patients with a lower risk profile.

Targeting high-risk patients for cardiovascular prevention of vascular dementia and Alzheimer disease requires assessment of aggregation of cardiovascular risk factors and detection of subclinical atherosclerosis in individuals.

In a cohort-study of 1270 dementia-free subjects aged 75 years or more, Qiu et al. scored cardiovascular risk factors at baseline and tracked incident dementia during a 9-year followup. A twofold increased risk for dementia (428 subjects including 328 with Alzheimer disease) was observed in subjects with an atherosclerotic profile (systolic BP $>160 \mathrm{mmHg}$ or diabetes or previous stroke) and cerebral hypoperfusion (diastolic BP $<70 \mathrm{mmHg}$ or pulse pressure $<70 \mathrm{mmHg}$, or heart failure) [60]. Similarly, de la Torre suggested that detection of subclinical atherosclerosis and carotid plaques using carotid artery ultrasound may identify patients at increased risk for subsequent cognitive impairment, thereby allowing reinforced preventive control of cardiovascular risk factors, a strategy which may ultimately reduce the incidence of dementia [61]. Whether translating such an approach to lower risk patients would be clinically relevant remains to be ascertained using appropriately designed trials targeting large populations and focusing on cognitive decline as primary outcome endpoints [62].

7.2. Age-Related Risk. Although prevalence and incidence of Alzheimer disease increase with age, further increase after the age 90 has been questioned, as approximately half of the centenarians (43\%) did not experience dementia [63]. In addition, pathological studies also showed that the distribution pattern of neurofibrillary tangles, senile plaque, microvascular impairment, and neuronal loss changes in extreme aging relative to the younger old [64]. As a result, the benefits expected from cardiovascular prevention of cognitive disorders in the oldest-old and centenarians may be more limited than in younger old.

7.3. Risk Control Across Populations. The benefit of cardiovascular risk factors control in preventing cognitive disorders 
among elderly may also largely vary across populations living in different geographical areas.

Dementia prevalence rates among people over 65 years ranges from $3 \%$ to $11 \%$, depending on diagnosis criteria (clinical, mostly DSM III, or MMSE-guided), age (Table 1), and countries (Tables 1 and 2). However, agerelated increases in prevalence are observed independently of the population studied (Table 1), with limited differences in prevalence across populations and geographical areas (Table 2).

The burden of cardiovascular risk factors and its impact on vascular dementia have also been reported to increase with age in patients in western countries [29,65-67]. Concomitantly, population-based surveys complemented by data from MONICA and INTERSALT showed a linear association of systolic blood pressure with age in men and women aged 30 to 70 years. This program, which encompassed 230 surveys and over 660000 participants worldwide showed that age-related increase in blood pressure is observed in all WHO subregions populations [68].

Although this may argue for some rationale for expecting similar results from cardiovascular prevention of cognitive decline among different populations, including in developing countries, trials to support such hypotheses remain to be performed.

\section{Conclusion}

Optimal treatment of cardiovascular risk factors prevents and decreases progression of vascular dementia and Alzheimer disease. As a 5-year delay in the onset of Alzheimer disease could reduce the prevalence of Alzheimer disease by $50 \%$, epidemiological forecasting estimate about $25 \%$ of the 5-fold increases in prevalence of dementia expected to occur until 2050 could effectively be prevented by optimal cardiovascular risk factors control $[3,61]$.

Thus, facing the worldwide burden of cardiovascular risk factors in a population growing in weight and in age continuously, slowing the incidence and progression of dementia may be a valuable challenge for cardiovascular prevention and cardiology practice. As life expectancy is expected to increase further in the decades to follow, limiting its agerelated counterparts such as Alzheimer disease may also be relevant in an individual perspective as well as in a community opportunity to reduce medical cost-expenditures.

\section{Conflicts of Interest}

The authors declare that there is no conflicts of interest.

\section{References}

[1] H. W. Querfurth and F. M. LaFerla, "Alzheimer's disease," New England Journal of Medicine, vol. 362, no. 4, pp. 329-344, 2010.

[2] I. McDowell, "Alzheimer's disease: insights from epidemiology," Aging, vol. 13, no. 3, pp. 143-162, 2001.

[3] R. Brookmeyer, E. Johnson, K. Ziegler-Graham, and H. M. Arrighi, "Forecasting the global burden of Alzheimer's disease," Alzheimer's and Dementia, vol. 3, no. 3, pp. 186-191, 2007.

[4] J. A. Yesavage, R. O'Hara, H. Kraemer et al., "Modeling the prevalence and incidence of Alzheimer's disease and mild cognitive impairment," Journal of Psychiatric Research, vol. 36, no. 5, pp. 281-286, 2002.

[5] C. S. Ivan, S. Seshadri, A. Beiser et al., "Dementia after stroke: the Framingham study," Stroke, vol. 35, no. 6, pp. 1264-1268, 2004.

[6] S. E. Vermeer, N. D. Prins, T. Den Heijer, A. Hofman, P. J. Koudstaal, and M. M. B. Breteler, "Silent brain infarcts and the risk of dementia and cognitive decline," New England Journal of Medicine, vol. 348, no. 13, pp. 1215-1222, 2003.

[7] J. C. De Groot, F. E. De Leeuw, M. Oudkerk et al., "Cerebral white matter lesions and cognitive function: the Rotterdam scan study," Annals of Neurology, vol. 47, no. 2, pp. 145-151, 2000.

[8] D. Liao, L. Cooper, J. Cai et al., "The prevalence and severity of white matter lesions, their relationship with age, ethnicity, gender, and cardiovascular disease risk factors: the ARIC study," Neuroepidemiology, vol. 16, no. 3, pp. 149-162, 1997.

[9] W. T. Longstreth, T. A. Manolio, A. Arnold et al., "Clinical correlates of white matter findings on cranial magnetic resonance imaging of 3301 elderly people: the cardiovascular health study," Stroke, vol. 27, no. 8, pp. 1274-1282, 1996.

[10] L. S. Honig, M. X. Tang, S. Albert et al., "Stroke and the risk of Alzheimer disease," Archives of Neurology, vol. 60, no. 12, pp. 1707-1712, 2003.

[11] J. A. Schneider, R. S. Wilson, J. L. Bienias, D. A. Evans, and D. A. Bennett, "Cerebral infarctions and the likelihood of dementia from Alzheimer disease pathology," Neurology, vol. 62, no. 7, pp. 1148-1155, 2004.

[12] J. A. Schneider, P. A. Boyle, Z. Arvanitakis, J. L. Bienias, and D. A. Bennett, "Subcortical infarcts, Alzheimer's disease pathology, and memory function in older persons," Annals of Neurology, vol. 62, no. 1, pp. 59-66, 2007.

[13] D. A. Snowdon, L. H. Greiner, J. A. Mortimer, K. P. Riley, P. A. Greiner, and W. R. Markesbery, "Brain infarction and the clinical expression of Alzheimer disease: the Nun Study," Journal of the American Medical Association, vol. 277, no. 10, pp. 813-817, 1997.

[14] M. M. Esiri, Z. Nagy, M. Z. Smith, L. Barnetson, A. D. Smith, and C. Joachim, "Cerebrovascular disease and threshold for dementia in the early stages of Alzheimer's disease," Lancet, vol. 354, no. 9182, pp. 919-920, 1999.

[15] J. A. Schneider, Z. Arvanitakis, W. Bang, and D. A. Bennett, "Mixed brain pathologies account for most dementia cases in community-dwelling older persons," Neurology, vol. 69, no. 24, pp. 2197-2204, 2007.

[16] I. Casserly and E. Topol, "Convergence of atherosclerosis and Alzheimer's disease: inflammation, cholesterol, and misfolded proteins," Lancet, vol. 363, no. 9415, pp. 1139-1146, 2004.

[17] M. Kivipelto, E. L. Helkala, M. P. Laakso et al., "Midlife vascular risk factors and Alzheimer's disease in later life: longitudinal, population based study," British Medical Journal, vol. 322, no. 7300, pp. 1447-1451, 2001.

[18] J. A. Luchsinger, C. Reitz, L. S. Honig, M. X. Tang, S. Shea, and R. Mayeux, "Aggregation of vascular risk factors and risk of incident Alzheimer disease," Neurology, vol. 65, no. 4, pp. 545-551, 2005.

[19] A. Hofman, W. A. Rocca, C. Brayne et al., "The prevalence of dementia in Europe: a collaborative study of 1980-1990 findings," International Journal of Epidemiology, vol. 20, no. 3, pp. 736-748, 1991. 
[20] K. Ritchie and D. Kildea, "Is senile dementia age-related or ageing-related: evidence from meta-analysis of dementia prevalence in the oldest-old," Lancet, vol. 346, no. 8980, pp. 931-934, 1995.

[21] K. J. Anstey, R. A. Burns, C. L. Birrell, D. Steel, K. M. Kiely, and M. A. Luszcz, "Estimates of probable dementia prevalence from population-based surveys compared with dementia prevalence estimates based on meta-analyses," BMC Neurology, vol. 10, article 62, 2010.

[22] M. J. Dong, B. Peng, X. T. Lin, J. Zhao, Y. R. Zhou, and R. H. Wang, "The prevalence of dementia in the People's Republic of China: a systematic analysis of 1980-2004 studies," Age and Ageing, vol. 36, no. 6, pp. 619-624, 2007.

[23] H. C. Chui, J. I. Victoroff, D. Margolin, W. Jagust, R. Shankle, and R. Katzman, "Criteria for the diagnosis of ischemic vascular dementia proposed by the State of California Alzheimer's Disease Diagnostic and Treatment Centers," Neurology, vol. 42, no. 3, pp. 473-480, 1992.

[24] A. Viswanathan, W. A. Rocca, and C. Tzourio, "Vascular risk factors and dementia: how to move forward?" Neurology, vol. 72, no. 4, pp. 368-374, 2009.

[25] J. A. Luchsinger, M. X. Tang, Y. Stern, S. Shea, and R. Mayeux, "Diabetes mellitus and risk of Alzheimer's disease and dementia with stroke in a multiethnic cohort," American Journal of Epidemiology, vol. 154, no. 7, pp. 635-641, 2001.

[26] E. S. C. Korf, L. R. White, P. H. Scheltens, and L. J. Launer, "Brain aging in very old men with type 2 diabetes: the Honolulu-Asia Aging Study," Diabetes Care, vol. 29, no. 10, pp. 2268-2274, 2006.

[27] A. L. Fitzpatrick, L. H. Kuller, D. G. Ives et al., "Incidence and prevalence of dementia in the Cardiovascular Health Study," Journal of the American Geriatrics Society, vol. 52, no. 2, pp. 195-204, 2004.

[28] J. E. Graham, K. Rockwood, B. L. Beattie et al., "Prevalence and severity of cognitive impairment with and without dementia in an elderly population," Lancet, vol. 349, no. 9068, pp. 1793 1796, 1997.

[29] R. Hébert, J. Lindsay, R. Verreault, K. Rockwood, G. Hill, and M. F. Dubois, "Vascular dementia: incidence and risk factors in the canadian study of health and aging," Stroke, vol. 31, no. 7, pp. 1487-1493, 2000.

[30] C. Berr, J. Wancata, and K. Ritchie, "Prevalence of dementia in the elderly in Europe," European Neuropsychopharmacology, vol. 15 , no. 4 , pp. 463-471, 2005.

[31] S. G. Riedel-Heller, A. Busse, and M. C. Angermeyer, "The state of mental health in old-age across the 'old' European Union-a systematic review," Acta Psychiatrica Scandinavica, vol. 113, no. 5, pp. 388-401, 2006.

[32] A. Lobo, P. Saz, G. Marcos et al., "Prevalence of dementia in a southern European population in two different time periods: the ZARADEMP Project," Acta Psychiatrica Scandinavica, vol. 116, no. 4, pp. 299-307, 2007.

[33] R. Nitrini, C. M. C. Bottino, C. Albala et al., "Prevalence of dementia in Latin America: a collaborative study of population-based cohorts," International Psychogeriatrics, vol. 21, no. 4, pp. 622-630, 2009.

[34] R. N. Kalaria, G. E. Maestre, R. Arizaga et al., "Alzheimer's disease and vascular dementia in developing countries: prevalence, management, and risk factors," The Lancet Neurology, vol. 7, no. 9, pp. 812-826, 2008.

[35] G. J. Biessels, I. J. Deary, and C. M. Ryan, "Cognition and diabetes: a lifespan perspective," The Lancet Neurology, vol. 7, no. 2, pp. 184-190, 2008.
[36] J. A. Luchsinger and D. R. Gustafson, "Adiposity, type 2 diabetes, and Alzheimer's disease," Journal of Alzheimer's Disease, vol. 16, no. 4, pp. 693-704, 2009.

[37] M. E. Risner, A. M. Saunders, J. F. B. Altman et al., "Efficacy of rosiglitazone in a genetically defined population with mildto-moderate Alzheimer's disease," Pharmacogenomics Journal, vol. 6, no. 4, pp. 246-254, 2006.

[38] G. E. Swan, C. DeCarli, B. L. Miller et al., "Association of midlife blood pressure to late-life cognitive decline and brain morphology," Neurology, vol. 51, no. 4, pp. 986-993, 1998.

[39] I. Skoog, B. Lernfelt, S. Landahl et al., "15-year longitudinal study of blood pressure and dementia," Lancet, vol. 347, no. 9009, pp. 1141-1145, 1996.

[40] F. E. De Leeuw, J. C. De Groot, M. Oudkerk et al., "A followup study of blood pressure and cerebral white matter lesions," Annals of Neurology, vol. 46, no. 6, pp. 827-833, 1999.

[41] C. Dufouil, O. Godin, J. Chalmers et al., "Severe cerebral white matter hyperintensities predict severe cognitive decline in patients with cerebrovascular disease history," Stroke, vol. 40, no. 6, pp. 2219-2221, 2009.

[42] J. H. Veldink, P. Scheltens, C. Jonker, and L. J. Launer, "Progression of cerebral white matter hyperintensities on MRI is related to diastolic blood pressure," Neurology, vol. 51, no. 1, pp. 319-320, 1998.

[43] E. S. C. Korf, L. R. White, P. Scheltens, and L. J. Launer, "Midlife blood pressure and the risk of hippocampal atrophy: the Honolulu Asia aging study," Hypertension, vol. 44, no. 1, pp. 29-34, 2004.

[44] H. Lithell, L. Hansson, I. Skoog et al., "The study on cognition and prognosis in the elderly (SCOPE): principal results of a randomized double-blind intervention trial," Journal of Hypertension, vol. 21, no. 5, pp. 875-886, 2003.

[45] I. Skoog, H. Lithell, L. Hansson et al., "Effect of baseline cognitive function and antihypertensive treatment on cognitive and cardiovascular outcomes: Study on COgnition and Prognosis in the Elderly (SCOPE)," American Journal of Hypertension, vol. 18, no. 8, pp. 1052-1059, 2005.

[46] R. Peters, N. Beckett, F. Forette et al., "Incident dementia and blood pressure lowering in the Hypertension in the Very Elderly Trial cognitive function assessment (HYVET-COG): a double-blind, placebo controlled trial," The Lancet Neurology, vol. 7, no. 8, pp. 683-689, 2008.

[47] C. Tzourio, C. Anderson, N. Chapman et al., "Effects of blood pressure lowering with perindopril and indapamide therapy on dementia and cognitive decline in patients with cerebrovascular disease," Archives of Internal Medicine, vol. 163, no. 9, pp. 1069-1075, 2003.

[48] C. Dufouil, J. Chalmers, O. Coskun et al., "Effects of blood pressure lowering on cerebral white matter hyperintensities in patients with stroke: the PROGRESS (Perindopril Protection Against Recurrent Stroke Study) Magnetic Resonance Imaging Substudy," Circulation, vol. 112, no. 11, pp. 1644-1650, 2005.

[49] F. Forette, M. L. Seux, J. A. Staessen et al., "Prevention of dementia in randomised double-blind placebo-controlled Systolic Hypertension in Europe (Syst-Eur) trial," Lancet, vol. 352, no. 9137, pp. 1347-1351, 1998.

[50] F. Forette, M. L. Seux, J. A. Staessen et al., "The prevention of dementia with antihypertensive treatment: new evidence from the systolic hypertension in Europe (syst-eur) study," Archives of Internal Medicine, vol. 162, no. 18, pp. 2046-2052, 2002.

[51] C. Reitz, M. X. Tang, J. Luchsinger, and R. Mayeux, "Relation of plasma lipids to Alzheimer disease and vascular dementia," Archives of Neurology, vol. 61, no. 5, pp. 705-714, 2004. 
[52] E. P. Helzner, J. A. Luchsinger, N. Scarmeas et al., "Contribution of vascular risk factors to the progression in Alzheimer disease," Archives of Neurology, vol. 66, no. 3, pp. 343-348, 2009.

[53] B. Wolozin, S. W. Wang, N. C. Li, A. Lee, T. A. Lee, and L. E. Kazis, "Simvastatin is associated with a reduced incidence of dementia and Parkinson's disease," BMC Medicine, vol. 5, Article ID 20, 2007.

[54] E. Zamrini, G. McGwin, and J. M. Roseman, "Association between statin use and Alzheimer's disease," Neuroepidemiology, vol. 23, no. 1-2, pp. 94-98, 2004.

[55] B. McGuinness, D. Craig, R. Bullock, and P. Passmore, "Statins for the prevention of dementia," Cochrane Database of Systematic Reviews, no. 2, Article ID CD003160, 2009.

[56] K. Rockwood, "Epidemiological and clinical trials evidence about a preventive role for statins in Alzheimer's disease," Acta Neurologica Scandinavica, vol. 114, no. 185, pp. 71-77, 2006.

[57] L. Wang, E. B. Larson, J. D. Bowen, and G. Van Belle, "Performance-based physical function and future dementia in older people," Archives of Internal Medicine, vol. 166, no. 10, pp. 1115-1120, 2006.

[58] N. Scarmeas, J. A. Luchsinger, N. Schupf et al., "Physical activity, diet, and risk of Alzheimer disease," Journal of the American Medical Association, vol. 302, no. 6, pp. 627-637, 2009.

[59] C. Féart, C. Samieri, V. Rondeau et al., "Adherence to a mediterranean diet, cognitive decline, and risk of dementia," Journal of the American Medical Association, vol. 302, no. 6, pp. 638-648, 2009.

[60] C. Qiu, W. Xu, B. Winblad, and L. Fratiglioni, "Vascular risk profiles for dementia and Alzheimer's disease in very old people: a population-based longitudinal study," Journal of Alzheimer's Disease, vol. 20, no. 1, pp. 293-300, 2010.

[61] J. C. de la Torre, "Carotid artery ultrasound and echocardiography testing to lower the prevalence of Alzheimer's disease," Journal of Stroke and Cerebrovascular Diseases, vol. 18, no. 4, pp. 319-328, 2009.

[62] K. Rockwood, L. E. Middleton, P. K. Moorhouse, I. Skoog, and S. E. Black, "The inclusion of cognition in vascular risk factor clinical practice guidelines," Clinical Interventions in Aging, vol. 4, pp. 425-433, 2009.

[63] J. Arnold, J. Dai, L. Nahapetyan et al., "Predicting successful aging in a population-based sample of Georgia centenarians," Current Gerontology and Geriatrics Research, vol. 2010, Article ID 989315, 2010.

[64] A. Von Gunten, K. Ebbing, A. Imhof, P. Giannakopoulos, and E. Kövari, "Brain aging in the oldest-old," Current Gerontology and Geriatrics Research, vol. 2010, Article ID 358531, 2010.

[65] R. C. Green, L. A. Cupples, R. Go et al., "Risk of dementia among white and African American relatives of patients with Alzheimer disease," Journal of the American Medical Association, vol. 287, no. 3, pp. 329-336, 2002.

[66] W. A. Kukull, R. Higdon, J. D. Bowen et al., "Dementia and Alzheimer disease incidence: a prospective cohort study," Archives of Neurology, vol. 59, no. 11, pp. 1737-1746, 2002.

[67] W. A. Rocca, A. Hofman, C. Brayne et al., "The prevalence of vascular dementia in Europe: facts and fragments from 19801990 studies," Annals of Neurology, vol. 30, no. 6, pp. 817-824, 1991.

[68] C. M. M. Lawes, S. Vander Hoorn, M. R. Law, P. Elliott, S. MacMahon, and A. Rodgers, "Blood pressure and the global burden of disease 2000-part 1: estimates of blood pressure levels," Journal of Hypertension, vol. 24, no. 3, pp. 413-422, 2006. 


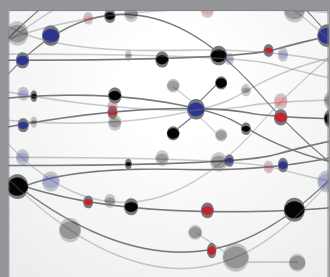

The Scientific World Journal
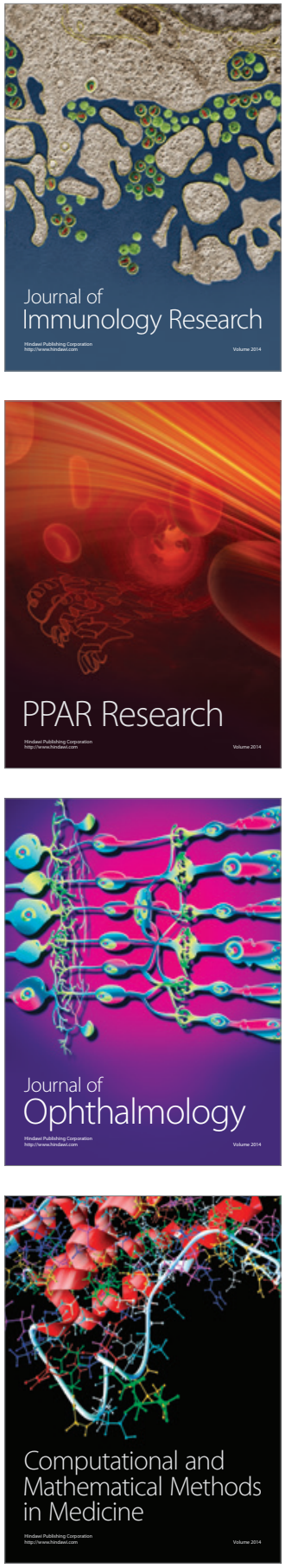

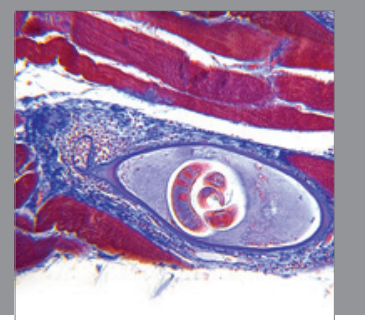

Gastroenterology

Research and Practice
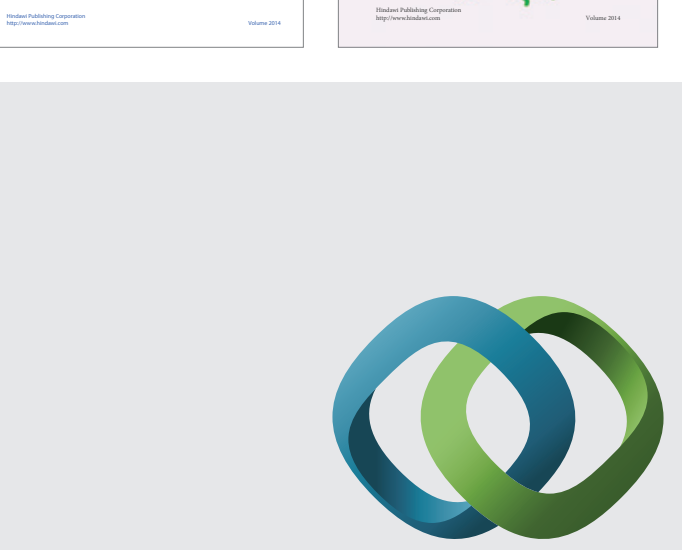

\section{Hindawi}

Submit your manuscripts at

http://www.hindawi.com
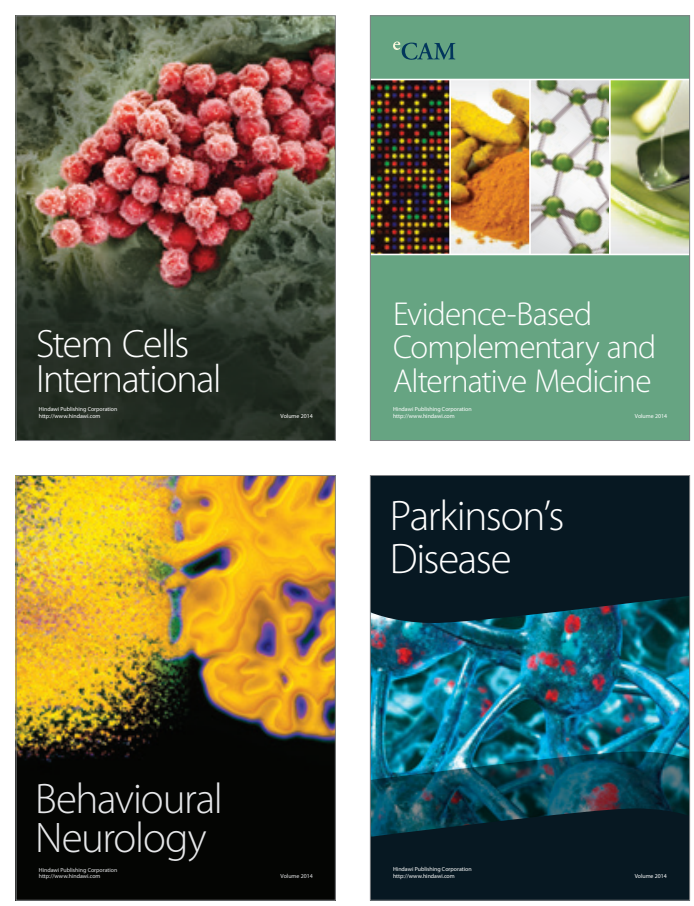

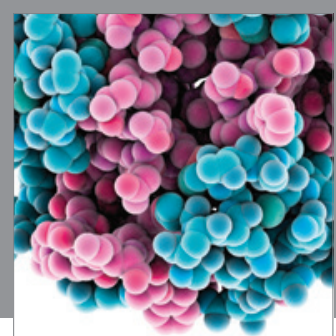

Journal of
Diabetes Research

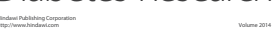

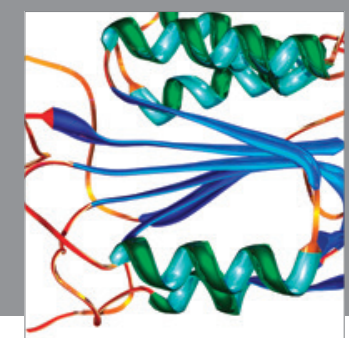

Disease Markers
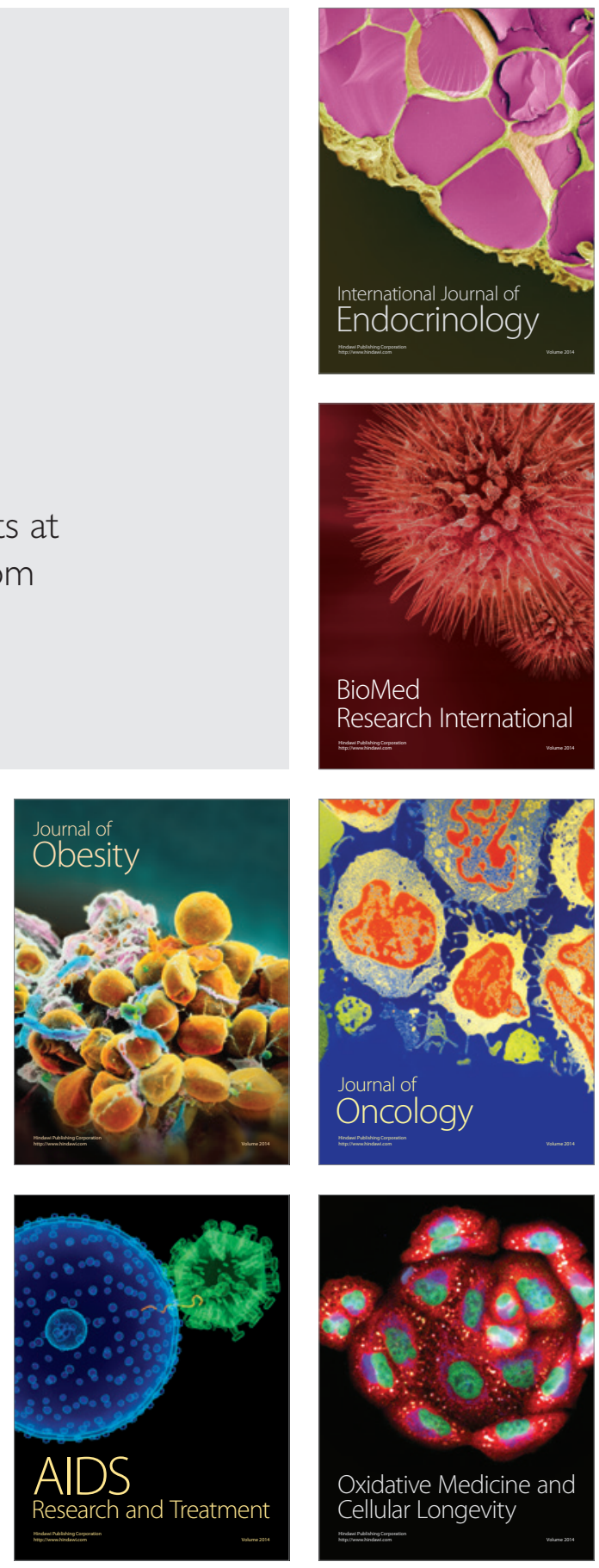